\title{
Analisis Pengaruh Variabel Keuangan dan Non Keuangan terhadap Underpricing pada Penawaran Saham Perdana di Bursa Efek Indonesia Periode 2016-2018
}

\author{
Jhoni Gunawan ${ }^{凶}$, Tri Gunarsih \\ Program Studi Manajemen, Universitas Teknologi Yogyakarta \\ e-mail: jhonigunawan1998@gmail.com
}

\begin{abstract}
Initial Public Offering (IPO) is the activity of offering company's first shares to the wider community. Generally, the phenomenon occured when conducting an IPO is underpricing, a condition that indicates the stock price in the primary market is lower than the first day price on the secondary market. The purpose of this study was to determine the effect of financial and non-financial variables on stock underpricing. The factors studied were debt to equity ratio, return on equity, underwriter's reputation, inflation rate and rupiah exchange rate. The population were companies that made initial public offerings on the IDX for the 2016-2018 period. The sample used is 99 companies obtained through purposive sampling method and analized by using multiple linear regression analysis. The results of this study indicate that the financial and non-financial variables simultaneously affect the underpricing of shares. However, the financial variable debt to equity ratio and return on equity, partially did not significantly influence underpricing. In addition, non-financial variables underwriter reputation and rupiah exchange rate were partially proven to have a significant negative effect on stock underpricing with a significance level of 5\%. Meanwhile, the non-financial variable inflation does not have a significant negative effect on underpricing.
\end{abstract}

Keywords: IPO, underpricing, financial variables, nonfinancial variables

\begin{abstract}
Abstrak
Initial Public Offering (IPO) merupakan kegiatan penawaran saham perdananya kepada masyarakat luas. Fenomena yang terjadi ketika akan melakukan IPO pada umumnya adalah underpricing. Underpricing adalah kondisi yang menunjukkan bahwa harga saham di pasar primer lebih rendah dibandingkan hari pertama di pasar sekunder. Tujuan dari penelitian ini untuk mengetahui pengaruh antara variabel keuangan dan non keuangan terhadap underpricing saham. Faktor-faktor yang diteliti adalah debt to equity ratio, return on equity, reputasi underwriter, tingkat inflasi dan kurs rupiah. Populasi dalam penelitian ini adalah perusahaan yang melakukan penawaran saham perdana di BEI periode 2016-2018. Sampel yang digunakan sebanyak 99 perusahaan yang didapat melalui metode purposive sampling dan metode analisis yang digunakan adalah analisis regresi linier berganda. Hasil penelitian ini menyatakan bahwa
\end{abstract}


variabel keuangan dan non keuangan secara simultan berpengaruh terhadap underpricing saham. Secara partial hasil penelitian pada variabel keuangan debt to equity ratio dan return on equity tidak berpengaruh secara signifikan terhadap underpricing. Variabel non keuangan reputasi underwriter dan kurs rupiah terbukti secara partial berpengaruh negatif signifikan terhadap underpricing saham dengan tingkat signifikansi 5\%. Sedangkan variabel non keuangan inflasi tidak berpengaruh negatif signifikan terhadap underpricing.

Kata Kunci: IPO, underpricing, keuangan, non keuangan

\section{PENDAHULUAN}

Penawaran umum perdana atau Initial Public Offering (IPO) adalah kegiatan penawaran saham atau efek lainnya yang dilakukan oleh emiten (perusahaan yang go public) kepada masyarakat berdasarkan tata cara yang diatur oleh UU Pasar Modal dan peraturan pelaksanaannya (Sunariyah, 2011). Fenomena yang kerap kali dihadapi perusahaan ketika melakukan penawaran saham perdana atau IPO adalah underpricing. Underpricing adalah kondisi dimana harga saham yang ditawarkan pada pasar perdana lebih rendah dibandingkan dengan harga saham ketika diperdagangkan di pasar sekunder (Hanafi, 2004). Kondisi underpricing merugikan bagi perusahaan yang melakukan go public, karena dana yang diperoleh dari publik tidak maksimal. Ketika melakukan initial public offering para pemilik perusahaan menginginkan agar situasi underpricing diminimalisasi, karena terjadinya underpricing akan menyebabkan transfer kemakmuran dari pemilik kepada para investor (Beatty, 1989) dalam Zainuddin (2014).

Caster \& Manaster (1990) dalam (Handayani, 2008) menjelaskan bahwa underpricing adalah hasil dari ketidakpastian harga saham pada pasar perdana. Menurut Tinic (1988) dalam teori risk averseunderwriter hypothesis, fenomena underpricing terjadi disebabkan oleh perilaku penjamin emisi yang berusaha menetapkan underpricing pada saham baru dengan tujuan mengurangi risiko dan biaya penjaminan. Adanya konflik kepentingan antara underwriter dan perusahaan emiten membuat harga saham perusahaan pada saat penawaran perdananya seringkali tidak mencerminkan harga saham sesungguhnya atau harga wajarnya (terjadi misprice).

Berdasarkan data statistik BEI, selama periode awal Januari 2016 sampai dengan Desember 2018 terdapat 107 perusahaan yang melakukan IPO. Setelah dilakukan pengamatan, dari 107 perusahaan tersebut, yang mengalami overpricing sebanyak 8 perusahaan $(7,48 \%)$, yang mengalami harga wajar 0 perusahaan sedangkan sisanya sebanyak 99 perusahaan $(92,52 \%)$ mengalami underpricing. Fenomena underpricing di pasar modal Indonesia sangat sering terjadi. Penyebab lain terjadinya underpricing karena adanya asimetri informasi. Menurut Beatty (1989), asimetri informasi dapat terjadi antara perusahaan emiten dengan underwriter (Model Baron) atau antara informed investor dengan uninformed investor (Model Rock). Pada model Baron (1982), penjamin emisi atau underwriter dianggap memiliki informasi tentang pasar yang lebih lengkap daripada emiten sedangkan terhadap calon investor, underwriter memiliki informasi yang lebih lengkap tentang kondisi emiten. Semakin besar asimetri informasi yang terjadi maka semakin besar risiko yang dihadapi investor. Rock (1986) melakukan penelitian mengenai underpricing dengan memperkenalkan winner's curse. Terjadinya winner's curse disebabkan adanya perbedaan informasi di antara kelompok informed investor dengan uninformed investor. 
Informed investor yang memiliki informasi lebih banyak mengenai perusahaan emiten akan membeli saham-saham IPO yang dianggap underpricing. Sementara kelompok uninformed karena kurang memiliki informasi mengenai perusahaan emiten, akan melakukan penawaran baik pada saham IPO yang overpriced maupun underpriced.

Tabel 1. Jumlah Perusahaan yang Melakukan IPO di BEI Periode Tahun 2016-2018

\begin{tabular}{cccccccc}
\hline \multirow{2}{*}{ Tahun } & \multirow{2}{*}{ Emiten } & \multicolumn{2}{c}{ Underpricing } & \multicolumn{2}{c}{ Wajar } & \multicolumn{2}{c}{ Overpricing } \\
& & Jumlah & Persen & Jumlah & Persen & Jumlah & Persen \\
\hline 2016 & 15 & 14 & 93,33 & 0 & 0 & 1 & 6,67 \\
2017 & 37 & 33 & 89,18 & 0 & 0 & 4 & 10,82 \\
2018 & 55 & 52 & 94,54 & 0 & 0 & 3 & 5,46 \\
Total & 107 & 99 & 92,52 & 0 & 0 & 8 & 7,48 \\
\hline
\end{tabular}

Sumber : Bursa Efek Indonesia (data diolah 2019)

Penelitian terkait isu underpricing telah banyak dilakukan sebelumnya. Akan tetapi, hasil dari penelitian yang dilakukan masih terjadi inkonsistensi antara hasil penelitian (research gap). Beberapa penelitian yang pernah dilakukan terkait isu underpricing yaitu penelitian yang dilakukan oleh Saefudin \& Gunarsih (2018). Penelitian Saefudin \& Gunarsih (2018) menemukan bahwa variabel debt to equity ratio, tidak berpengaruh terhadap underpricing. Berbeda dengan penelitian sebelumnya, Wahyusari (2013) menganalisis faktor-faktor yang mempengaruhi underpricing saham Saat IPO di BEI mengungkapkan bahwa variabel keuangan debt to equity ratio berpengaruh negatif terhadap underpricing. Debt to equity ratio menunjukkan kemampuan perusahaan untuk membayar semua hutang perusahaan dengan equity yang dimilikinya. Semakin besar hutang yang dimiliki perusahaan, maka semakin besar pula beban bunga yang harus dibayarkan oleh perusahaan yang akan mengurangi return perusahaan.

Variabel keuangan lain yang menjelaskan underpricing yaitu return on equity. Penelitian yang dilakukan oleh Alviani \& Lasmana (2015) mengenai isu underpricing membuktikan bahwa return on equityberpengaruhnegatifsignifikanterhadap tingkat underpricing saham secara parsial. Akan tetapi hasil penelitian yang dilakukan oleh Rosyidah (2014) membuktikan tidak ada pengaruh antara return on equity terhadap tingkat underpricing.

Penjamin emisi (underwriter) adalah pihak yang berperan dalam menetapkan harga pada saham perdana yang akan ditawarkan. Selain itu, underwriter mempunyai tugas sebagai penjamin atas penjualan saham perdana perusahaan. Penelitian oleh Ratnasari \& Hudiwinarsih (2013) dan Assari dkk. (2014) menemukan bahwa reputasi underwriter berpengaruh secara signifikan terhadap underpricing, dengan tingkat signifikansi 5\%. Namun, menurut temuan Wahyusari (2013) dan Permanisuci (2015) membuktikan bahwa reputasi underwriter tidak berpengaruh signifikan terhadap tingkat underpricing.

Variabel non keuangan lain pada penelitian sebelumnya yang menjelaskan pengaruh terhadap underpricing adalah faktor yang berasal dari luar perusahaan yang terdiri dari inflasi dan kurs rupiah. Inflasi merupakan salah satu indikasi tentang adanya ketidakstabilan perekonomian di Indonesia. Investor akan mempertimbangkan investasi dengan melihat laju inflasi pada negara di mana emiten berada karena tingkat 
inflasi tinggi akan mengakibatkan efek yang merugikan bagi emiten. Tingginya tingkat inflasi akan mengakibatkan tingginya ongkos produksi perusahaan dan berakibat menurunnya profit perusahaan. Inflasi menimbulkan ketidakpastian yang dihadapi investor, maka ekspektasi investor untuk tingkat underpricing akan tinggi (Wibowo, 2005). Penelitian yang dilakukan oleh Wijaya (2013) dan Saifudin \& Rahmawati (2016) membuktikan tingkat inflasi berpengaruh negatif dan signifikan terhadap underpricing. Sementara itu penelitian yang dilakukan oleh Wibowo (2005), Ratnasari \& Hudiwinarsih (2013), dan Diasih dkk. (2017) membuktikan tingkat inflasi tidak berpengaruh terhadap tingkat underpricing.

Menurut penelitian Ocktavia (2007) nilai tukar rupiah/US\$ mempunyai pengaruh positif terhadap IHSG. Jika kurs turun, maka harga saham juga akan turun, dan begitu pula sebaliknya. Penelitian yang dilakukan oleh Ahmad dkk. (2013) menyatakan kurs rupiah berpengaruh positif secara signifikan terhadap underpricing dengan tingkat signifikansi $10 \%$ sejalan dengan penelitian yang dilakukan oleh Yandes (2013) membuktikan variabel kurs rupiah berpengaruh terhadap tingkat underpricing. Sementara itu, penelitian yang dilakukan oleh Rachmadhanto \& Raharja (2014), dan Diasih dkk. (2017) membuktikan kurs rupiah tidak berpengaruh terhadap underpricing.

Berdasarkan uraian di atas, masih ditemukan fenomena tingginya tingkat underpricing pada perusahaan yang melakukan IPO yang secara teori seharusnya tingkat underpricing ini dapat diminimalisir. Tujuan penelitian ini adalah untuk menguji pengaruh variabel keuangan dan non keuangan terhadap underpricing pada penawaran saham perdana di Bursa Efek Indonesia periode 2016-2018 (studi pada perusahaan yang terdaftar di BEI tahun 2016-2018).

\section{Penawaran Umum Perdana (IPO)}

Initial Public Offering atau IPO adalah kegiatan perusahaan untuk menjual sahamnya kepada publik melalui pasar modal untuk pertama kalinya (Handayani, 2008). Dalam Undang-undang No. 8 tahun 1995 tentang Pasar Modal mendefinisikan penawaran umum perdana (IPO) sebagai "kegiatan penawaran efek yang dilakukan oleh emiten untuk menjual efek kepada masyarakat berdasarkan tata cara yang diatur dalam undang-undang dan peraturan pelaksanaannya". Adapun yang dimaksud sebagai efek adalah surat berharga yaitu surat pengakuan hutang, surat berharga komersial, saham, obligasi, tanda bukti hutang, unit penyertaan kontrak investasi kolektif, kontrak berjangka atas efek dan setiap derivatif dari efek.

\section{Underpricing}

Underpricing adalah suatu keadaan dimana harga saham yang diperdagangkan di pasar perdana lebih rendah dibandingkan ketika diperdagangkan di pasar sekunder dan memungkinkan investor memperoleh initial return yang positif (Wibowo, 2005). Sedangkan menurut (Hartono, 1998) underpricing merupakan initial return yaitu harga penawaran di pasar primer selalu lebih rendah dibandingkan dengan harga pembukaan atau penutupan pada hari pertama perdagangan di pasar sekunder. Dari paparan di atas maka dapat ditarik kesimpulan bahwa para pemilik perusahaan menginginkan situasi underpricing diminimumkan agar perusahaan dapat menghimpun dana dari masyarakat secara maksimal dan mencegah terjadinya transfer kemakmuran dari pemilik perusahaan kepada para investor. Berikut adalah teori-teori yang menjelaskan mengapa dapat terjadinya situasi underpricing menurut Tinic (1988): 
1. Risk averse-underwriter hypothhesis

Bahwa terjadinya underpricing disebabkan oleh perilaku penjamin emisi yang berusaha menetapkan underpricing pada saham baru dengan tujuan mengurangi risiko dan biaya penjaminan. Dengan kata lain, underpricing sebagai metode yang digunakan oleh penjamin emisi untuk mengurangi kemungkinan berakhirnya dengan ketidakberhasilan penjamin emisi (underwriter) dalam melakukan penjaminan.

2. Monopsony-power hypothesis

Bahwa penjamin emisi sengaja mengurangi harga saham dengan tingkatan diskonto tertentu dengan harapan dapat memperoleh pendapatan secara tidak langsung. Ketika perusahaan emiten tersebut go public, mereka cenderung membuat harga sahamnya sendiri underpriced, seperti saham perusahaan lain. Hal seperti ini, berhasil meyakinkan klien (calon emiten) dan badan pengatur pasar modal bahwa underpricing adalah hal yang normal terjadi pada IPO.

3. Speculative-bubble hypothesis

Terjadinya underpricing berhubungan dengan keinginan spekulasi para investor yang tidak mendapat alokasi saham baru yang oversubscribed pada saat penawaran perdana, dan menyatakan bahwa pendapatan abnormal positif pada awalnya akan diikuti pendapatan abnormal negatif.

\section{Asymmetric-information hypothesis}

Mengasumsikan penjamin emisi memiliki informasi yang lebih lengkap mengenai permintaan saham dibandingkan dengan emiten, dan menjelaskan dua kelompok investor potensial yang menyebabkan informasi asimetris, yaitu informed investor dan uninformed investor. Informed investor yang memiliki informasi lebih banyak mengenai perusahaan emiten akan membeli sahamsaham IPO yang dianggap underpricing. Sementara kelompok uninformed karena kurang memiliki informasi mengenai perusahaan emiten, akan melakukan penawaran baik pada saham IPO yang overpriced maupun underpriced.

\section{Debt to Equity Ratio terhadap Tingkat Underpricing}

Debt to Equity Ratio (DER) merupakan rasio leverage yang diukur dari seluruh total hutang jangka panjang perusahaan terhadap total ekuitas yang dimiliki. Semakin besar DER menunjukkan bahwa perusahaan menggunakan pendanaan bersumber dari kreditor tinggi, yang akan meningkatkan risiko finansial atau risiko kegagalan perusahaan untuk mengembalikan pinjaman yang nantinya akan mempengaruhi tingkat return yang akan diterima oleh investor di masa yang akan datang.

Hasil penelitian yang dilakukan oleh Wahyusari (2013) menunjukkan bahwa variabel keuangan Debt to Equity Ratio berpengaruh signifikan positif terhadap tingkat underpricing. Hal ini juga selaras dengan penelitian yang dilakukan oleh Arfandy (2013) dan Sulisyawati \& Wirajaya (2017) yang menemukan financial leverage berpengaruh positif terhadap underpricing pada penawaran saham perdana. Berdasarkan hasil temuan tersebut maka disusun hipotesis sebagai berikut:

$\mathrm{H}_{1}$ : Debt to Equity Ratio (DER) berpengaruh positif terhadap tingkat underpricing

\section{Return On Equity (ROE) terhadap Tingkat Underpricing}

Return on equity (ROE) merupakan rasio perbandingan antara net income after tax dengan total equity. Pertimbangan menggunakan variabel keuangan ROE ini karena kemampuan perusahaan untuk 
menghasilkan laba pada masa mendatang merupakan indikator dan pemberian informasi kepada pihak luar mengenai keberhasilan efektifitas operasi perusahaan Yolana \& Martani (2005).

Hasil penelitian yang dilakukan oleh Yandes (2013) menunjukkan bahwa variabel keuangan ROE berpengaruh negatif terhadap tingkat underpricing. Senada dengan hasil penelitian yang dilakukan oleh Alviani \& Lasmana (2015) dan Haska dkk. (2017) yang menunjukkan ROE berpengaruh negatif signifikan terhadap underpricing. Berdasarkan kerangka pemikiran tersebut, maka disusun hipotesis sebagai berikut:

$\mathrm{H}_{2}$ : Return on Equity (ROE) berpengaruh negatif terhadap tingkat underpricing

\section{Reputasi Underwriter terhadap Tingkat Underpricing}

Undang-Undang Pasar Modal No. 8 tahun 1995 menyatakan bahwa underwiter sebagai pihak yang membuat kontrak dengan perusahaan emiten dengan atau tanpa kewajiban untuk membeli lagi sisa saham yang tidak terjual pada saat melakukan penawaran saham perdana. Underwriter bereputasi tinggi akan dapat mengurangi konflik yang terjadi dengan menetapkan harga saham perdana sesuai dengan kondisi perusahaan, sehingga akan mengurangi underpricing (Bachtiar \& Syafruddin, 2012).

Hasil temuan Wibowo (2005) pada analisis faktor-faktor yang mempengaruhi tingkat underpricing pada perusahaan perbankan yang IPO periode 1999-2003 mengungkapkan bahwa reputasi underwriter berpengaruh negatif terhadap tingkat underpriced. Hal senada juga ditemukan oleh Diasih dkk. (2017) yang menunjukkan bahwa reputasi underwriter memiliki pengaruh negatif terhadap tingkat underpricing. Artinya bahwa penggunaan underwriter yang bereputasi baik, maka perusahaan dapat mengurangi resiko atas penawaran sahamnya kepada publik pada saat penawaran umum perdana sehingga resiko underpricing dapat diperkecil. Berdasarkan kerangka pemikiran tersebut, maka disusun hipotesis sebagai berikut:

$\mathrm{H}_{3}$ : Reputasi underwriter berpengaruh negatif terhadap tingkat underpricing

\section{Inflasi terhadap Underpricing}

Inflasi adalah kecenderungan terjadinya peningkatan harga produk-produk secara keseluruhan sehingga terjadi penurunan daya beli uang (Tandelilin, 2010). Menurut Putong (2009), inflasi adalah kecenderungan dari harga-harga untuk menaik secara umum dan terus menurus. Inflasi dapat juga dikatakan suatu gejala terus naiknya harga-harga barang dan berbagai faktor produksi umum, secara terus-menerus dalam periode tertentu.

Penelitian yang dilakukan oleh Yandes (2013) mengenai Fenomena underpricing saham yang dipengaruhi faktor internal dan eksternal (studi pada perusahaan go public yang terdaftar di BEI tahun 2007-2010) menunjukkan bahwa inflasi memiliki pengaruh negatif terhadap underpricing. Hal senada juga ditemukan oleh Saifudin \& Rahmawati (2016) mengenai pengaruh informasi akuntansi dan non akuntansi terhadap underpricing ketika initial public offering di BEI periode 2009-2013 menunjukkan bahwa inflasi berpengaruh secara signifikan terhadap tingkat underpricing. Berdasarkan kerangka pemikiran tersebut dapat disusun hipotesis sebagai berikut:

$\mathrm{H}_{4}$ : Inflasi berpengaruh negatif terhadap tingkat underpricing

\section{Kurs Rupiah terhadap Underpricing}

Kurs merupakan salah satu variabel non keuangan atau variabel eksternal perusahaan yang mampu menggambarkan keadaan pasar dan merupakan salah satu leading indicator harga saham. Apabila nilai rupiah naik maka permintaan saham di pasar sekunder akan 
meningkat, sehingga harga di pasar perdana akan rendah atau terjadi underpricing (Diasih dkk., 2017).

Penelitian yang dilakukan oleh Yolana \& Martani (2005) menemukan bahwa ratarata kurs berpengaruh signifikan terhadap underpricing. Hal ini senada dengan temuan Yandes (2013) dalam penelitiannya yang menemukan bahwa kurs rupiah berpengaruh cukup signifikan terhdapa underpricing. Berdasarkan kerangka pemikiran di atas, dapat disusun hipotesis sebagai berikut:

$\mathrm{H}_{5}$ : Kurs rupiah berpengaruh positif terhadap tingkat underpricing.

\section{METODE PENELITIAN}

Populasi pada penelitian ini adalah seluruh perusahaan go public yang melakukan initial public offering di BEI. Sampel yang dipilih pada penelitian ini didasarkan dengan metode purposive sampling dengan kriteria; (1) perusahaan go public yang melakukan IPO atau penawaran saham perdana di BEI pada periode 2016 sampai dengan 2018; (2) perusahaan yang mengalami underpricing.

Penelitian ini menggunakan data sekunder. Data yang digunakan pada penelitian ini berupa: (1) Daftar emiten yang melakukan IPO periode 2016 sampai dengan 2018 yang diperoleh dari website IDX; (2) Harga saham penawaran perdana di pasar primer diperoleh dari Indonesian Capital Market Directory (ICMD), sedangkan harga penutupan hari pertama di pasar sekunder (closing price) diperoleh dari website IDX dan Yahoo Finance; (3) Daftar debt to equity ratio, return on equity, dan nama underwriter diperoleh dari annual report untuk kekurangan data lainnya diambil dari ICMD dari 2016-2018; (4) Daftar reputasi underwriter periode 2016 sampai dengan 2018 diperoleh dari website IDX Fact Book tahunan; (5) Daftar tingkat inflasi dan kurs rupiah periode 2016 sampai dengan 2018 diperoleh dari website Bank
Indonesia; (6) Laporan keuangan dan annual report masing-masing perusahaan diperoleh dari website IDX.

\section{Variabel Penelitian}

Variabel dependen pada penelitian ini adalah tingkat underpricing. Tingkat underpricing ini diproksi dengan penghitungan initial return yang positif dari perusahaan-perusahaan yang melakukan IPO. Initial return pada penelitian ini dihasilkan dari selisih positif penutupan harga saham pada hari pertama di pasar sekunder dengan harga saham penawaran perdana di pasar primer dibagi dengan harga saham penawaran perdana Ardiansyah (2004). Rumus yang digunakan untuk menghitung initial return positif sebagai berikut:

$I R=\frac{\text { Opening Pricing }- \text { Offering Pricing }}{\text { Offering Pricing }} \times 100 \%$

Keterangan:

IR

: Initial Return (Return Awal)

Opening Price : Harga pembukaan hari pertama di pasar sekunder

Offering Price : Harga penawaran perdana

Penelitian ini menggunakan lima variabel independen, yaitu debt to equity ratio, return on equity, reputasi underwriter, inflasi, dan kurs rupiah.

\section{Debt to Equity Ratio (DER)}

$$
D E R=\frac{\text { Total Debt }}{\text { Total Equity }} \times 100 \%
$$

Keterangan:

DER : Debt to Equity Ratio

Total Debt : Total kewajiban

Total Equity: Total modal atau ekuitas

Return on Equity (ROE)

$R O E=\frac{\text { Net Income After Tax }}{\text { Total Equity }} \times 100 \%$

Keterangan:

ROE : Return on Equity 
Net Income After Tax : Pendapatan bersih setelah pajak

Total Equity : Total modal atau ekuitas

\section{Reputasi Underwriter}

Reputasi Underwriter merupakan variabel dummy yaitu variabel yang bersifat kualitatif yang dikuantitatifkan. Penentuan tinggi rendahnya reputasi underwriter dilakukan dengan cara memeringkatkan underwriter. Pemeringkatan dilakukan dengan memberikan angka 1 untuk underwriter yang masuk ke dalam 20 top besar dari 50 most active IDX members in total trading frequency dan angka 0 untuk underwriter yang tidak masuk kedalam 20 top besar dari 50 most active IDX members in total trading frequency (Gunarsih dkk., 2014). Data reputasi underwriter yang digunakan dalam penelitian ini diperoleh dari IDX Fact Book.

\section{Inflasi}

Tingkat inflasi yang digunakan dalam penelitian ini adalah data tingkat inflasi yang ditetapkan oleh Bank Indonesia satu bulan saat emiten melakukan IPO yang dinyatakan dalam skala rasio/persentase.

\section{Kurs Rupiah}

Kurs merupakan variabel makroekonomi yang mampumenggambarkan keadaan pasar dan merupakan salah satu leading indicator harga saham. Kurs atau nilai tukar rupiah adalah harga rupiah terhadap mata uang negara lain. Data besarnya ratarata kurs disesuaikan saat emiten melakukan IPO.

\section{Model Regresi}

Persamaan regresi yang digunakan sebagai berikut:

$$
\begin{aligned}
Y & =\alpha+\beta_{1} \times D E R+\beta_{2} \times R O E+\beta_{3} \times R_{e p} \text { Und } \\
& +\beta_{4} \times \text { Inf }+\beta_{5} \times \text { Kurs_Rp }_{-} R
\end{aligned}
$$

Keterangan :

Y : Tingkat Underpricing

$\begin{array}{ll}\alpha & : \text { Konstanta } \\ \text { DER } & : \text { Debt To Equity Ratio } \\ \text { ROE } & : \text { Return On Equity } \\ \text { Rep_Und: Reputasi Underwriter } \\ \text { Inf } \quad: \text { Inflasi } \\ \text { Kurs_Rp }: \text { Kurs Rupiah } \\ \beta_{1} \quad \text { : Koefisien regresi DER } \\ \beta_{2} \quad \text { : Koefisien regresi ROE } \\ \beta_{3} \quad \text { : Koefisien regresi Reputasi } \\ \beta_{4} \quad \text { Underwriter } \\ \beta_{5} \quad \text { Koefisien regresi Inflasi } \\ \mathrm{e} & \text { : Reefisien regresi Kurs Rupiah }\end{array}$

\section{HASIL DAN PEMBAHASAN}

Statistik deskriptif adalah sebagaimana Tabel 2, dengan nilai minimum, maksimum, rata-rata (mean) dan simpangan baku (standard deviation) perusahaan sampel.

Tabel 2. Statistik Deskriptif

\begin{tabular}{lrrrrr}
\hline Variabel & N & Min & Max & Mean & Std. Dev \\
\hline Underpricing & 99 & 0,45 & 70,00 & 47,4072 & 23,90944 \\
DER (X1) & 99 & $-134,31$ & 342,20 & 19,1227 & 55,62927 \\
ROE (X2) & 99 & $-24,23$ & 229,54 & 9,7626 & 25,53019 \\
Rep Under & 99 & 0 & 1 & 0,33 & 0,474 \\
(X3) & & & & & \\
Inflasi (X4) & 99 & 2,88 & 4,42 & 3,4839 & 0,46038 \\
$\begin{array}{l}\text { Kurs Rp } \\
\text { (X5) }\end{array}$ & 99 & 12.926 & 15.253 & $13.941,34$ & 666,412 \\
\hline Sumber: Olahan data 2019 & & & & \\
\hline
\end{tabular}

Hasil analisis regresi yang dipergunakan untuk menguji hipotesis adalah sebagaimana Tabel 3. Nilai $F$ adalah 6,388 signifikan secara statistik pada $\alpha 1 \%$.

Tabel 3. Hasil Persamaan Regresi

\begin{tabular}{lrrrl|}
\hline \multicolumn{1}{c}{ Variabel } & \multicolumn{1}{c}{ B } & $\begin{array}{c}\text { Std. } \\
\text { Error }\end{array}$ & t & Sig. \\
\hline (Constant) & $-109,409$ & 66,699 & $-1,640$ & 0,104 \\
DER & 0,004 & 0,038 & 0,095 & 0,925 \\
ROE & $-0,123$ & 0,082 & $-1,506$ & 0,135 \\
Rep_Und & $-21,780$ & 4,337 & $-5,022$ & 0,000 \\
Inflasi & 5,906 & 6,366 & 0,928 & 0,356 \\
Kurs Rupiah & 0,012 & 0,004 & 2,619 & 0,010 \\
\hline
\end{tabular}

Catatan: Model regresi sudah diuji Linearitas, Normalitas Residual, Autokorelasi, Multikolinieritas dan Heteroskedastisitas

Sumber: Olahan Data, 2019 


\section{Pengaruh Variabel DER terhadap Underpricing}

Hasil pengujian pada variabel DER memiliki nilai $\mathrm{t}$ sebesar 0,095 dengan $\rho$ value $0,925(>5 \%)$ atau lebih besar dari tingkat kepercayaan 0,10 yang artinya $\mathrm{H}_{1}$ yang diajukan penelitian ini di mana Debt to Equity Ratio (DER) berpengaruh positif terhadap besarnya tingkat underpricing pada perusahaan yang melakukan initial public offering, ditolak. Hasil penelitian ini sejalan dengan temuan penelitian yang dilakukan Handayani (2008), Wijaya (2013), dan Noviani (2017) yang menyatakan bahwa Debt to Equity Ratio (DER) tidak berpengaruh terhadap underpricing.

Variabel DER menunjukkan tidak berpengaruh signifikan terhadap tingkat underpricing. Alasan mengapa DER tidak berpengaruh terhadap underpricing menurut Yandes(2013)karenarasioyang menunjukkan rasio hutang ini lebih mencerminkan resiko perusahaan yang relatif tinggi sehingga mengakibatkan ketidakpastian harga saham dan berdampak pada return saham yang nantinya akan diterima investor. Akibatnya investor cenderung menghindari sahamsaham yang memiliki DER tinggi.

\section{Pengaruh Variabel ROE terhadap Underpricing}

Pada penelitian ini variabel ROE memiliki nilai t sebesar -1,506 dengan $\rho$ value $0,135(>5 \%)$, yang artinya $\mathrm{H} 2$ ditolak karena hipotesis yang diajukan dalam penelitian ini adalah ROE berpengaruh negatif terhadap underpricing. Namun, hasil uji statistik $\mathrm{t}$ dalam penelitian ini menunjukkan bahwa variabel keuangan ROE tidak berpengaruh terhadap tingkat underpricing. Hal ini senada dengan temuan penelitian yang dilakukan oleh Rosyidah (2014) dan Rachmadhanto \& Raharja (2014) yang membuktikan tidak ada pengaruh antara return on equity terhadap tingkat underpricing.
Penyebab ROE tidak berpengaruh signifikan terhadap underpricing yaitu karena jenis industri yang berbeda menyebabkan kemampuan perusahaan dalam menciptakan profit berbeda pula. Tidak setiap jenis industri dapat menciptakan profit yang tinggi tiap tahunnya. Perusahaan dengan kegiatan produksi jangka panjang biasanya tidak menunjukkan profit yang tinggi secara konstan. Contohnya adalah industri pertambangan yang nilai investasinya sangat besar dan jangka panjang, biasanya return yang dicapai tidak terlalu besar bila dibandingkan ekuitasnya.

\section{Pengaruh Variabel Reputasi Underwriter terhadap Underpricing}

Variabel reputasi underwriter memiliki nilai t sebesar $-5,022$ dengan $\rho$ value 0,000 $(<5 \%)$ yang berarti bahwa variabel reputasi underwriter memiliki pengaruh negatif signifikan terhadap underpricing. Hasil ini mendukung hipotesis ketiga yang diajukan karena berhasil menunjukkan adanya pengaruh yang negatif signifikan terhadap underpricing sehingga $\mathrm{H} 3$ diterima. Temuan ini juga serupa dengan temuan Wibowo (2005), Diasih dkk. (2017) di mana reputasi underwriter berpengaruh negatif signifikan terhadap underpricing. Hasil ini sesuai dengan teori asymmetric information di mana reputasi underwriter yang baik dapat mengurangi kesenjangan informasi sehingga dapat mengurangi ketidakpastian di pasar sekunder. Dengan reputasi yang bagus, IPO dapat berjalan lancar sehingga underpricing dapat diminimalisir.

\section{Pengaruh Variabel Inflasi terhadap Underpricing}

Hasil pengujian pada variabel inflasi memiliki nilai $\mathrm{t}$ sebesar 0,928 dengan $\rho$ value 0,356 atau lebih besar dari tingkat kepercayaan 0,10 yang artinya $\mathrm{H} 4$ yang diajukan penelitian ini di mana inflasi berpengaruh negatif terhadap besarnya tingkat underpricing pada perusahaan yang 
melakukan initial public offering, ditolak. Hasil ini juga konsisten dengan temuan Ratnasari \& Hudiwinarsih (2013) dan Diasih dkk. (2017) yang menemukan bahwa variabel inflasi tidak berpengaruh terhadap variabel underpricing. Dalam penelitian ini menghasilkan temuan bahwa tingkat inflasi tidak berpengaruh terhadap underpricing saham. Hal tersebut dikarenakan kondisi perekonomian Indonesia yang tidak stabil dengan nilai inflasi yang mudah berubah-ubah setiap saat. Selain itu, tidak berpengaruhnya tingkat inflasi terhadap underpricing dalam penelitian ini diduga karena penggunaan nilai closing price sehari setelah penawaran saham perdana dalam perhitungan underpricing. Penilaian inflasi dilakukan setiap bulan oleh $\mathrm{BI}$, apabila closing price yang dipakai hanya selisih sehari dari offering price, berarti tingkat underpricing yang dihitung belum terpengaruh langsung oleh inflasi.

\section{Pengaruh Variabel Kurs Rupiah Terhadap Underpricing}

Hasil penelitian pada variabel kurs rupiah memiliki nilai t sebesar 2,619 dengan $\rho$ value $0,010(<5 \%)$ yang berarti bahwa variabel kurs rupiah memiliki pengaruh positif signifikan terhadap underpricing, sehingga H5 diterima. Temuan hasil penelitian ini sejalan dengan hasil penelitian Ahmad dkk. (2013) yang menyatakan variabel kurs rupiah berpengaruh positif signifikan terhadap tingkat underpricing.

Ahmad dkk. (2013) menyebutkan pada kondisi ini kurs atau nilai tukar adalah harga suatu mata uang terhadap mata uang lainnya atau nilai dari suatu mata uang terhadap nilai mata uang lainnya. Kurs merupakan informasi eksternal yang cukup dipertimbangkan dalam perdagangan saham di seluruh dunia tak terkecuali di Indonesia. Naik turunnya nilai Rupiah terhadap uang asing menyebabkan naik turunnya permintaan saham di pasar modal oleh investor, sehingga dapat disimpulkan bahwa kurs rupiah berpengaruh terhadap underpricing.

\section{SIMPULAN DAN SARAN}

Berdasarkan hasil penelitian mengenai pengaruh variabel keuangan dan variabel non keuangan terhadap tingkat underpricing saham pada perusahaan yang melakukan initial public offering di Bursa Efek Indonesia tahun 2016-2018 dan analisis yang didukung oleh teori-teori yang melandasi, serta hasil pembahasan pada bab-bab sebelumnya, maka diambil beberapa kesimpulan.

Variabel debt to equity ratio tidak berpengaruh signifikan terhadap underpricing, hal ini dibuktikan tingkat sig t 0,095 > 0,05. Hasil ini menunjukkan bahwa investor mempertimbangkan tingginya rasio hutang perusahaan yang pada akhirnya investor cenderung menghindari saham-saham yang memiliki DER tinggi. Selain itu DER yang tinggi mengakibatkan ketidakpastian harga saham dan berdampak pada return saham yang nantinya akan diterima investor.

Variabel return on equity memiliki nilai t sebesar $-1,506$ dengan $\rho$ value 0,135 $(>5 \%)$ yang artinya tidak berpengaruh siginifikan terhadap underpricing. Return on equity tidak berpengaruh terhadap tingkat underpricing dapat disebabkan oleh data ROE di dalam penelitian ini memiliki nilai range yang jauh. Nilai terendah (minimum) sebesar -24,623 sedangkan nilai tertinggi (maksimum) sebesar 229,54\%. Selisih yang terlampaui jauh tersebut dapat menyebabkan hasil penelitian ini menjadi tidak signifikan.

Variabel reputasi underwriter memiliki pengaruh negatif signifikan terhadap underpricing. Hal ini dibuktikan dari nilai t sebesar -5,022 dengan $\rho$ value 0,000 ( $<$ $5 \%$ ). Bagi underwriter yang memiliki reputasi tinggi, tentunya berani memberikan 
harga yang tinggi pula sebagai konsekuensi dari kualitas penjaminannya. Underwriter yang bereputasi tinggi tentu memberikan informasi dan data selengkap mungkin untuk meningkatkan citra dan mengurangi kesenjangan informasi sehingga dapat mengurangi ketidakpastian di pasar sekunder. Semakin kecil ketidakpasttian maka tingkat underpricing semakin kecil.

Variabel inflasi tidak berpengaruh terhadap underpricing, hal ini dibuktikan dari nilai $\mathrm{t}$ sebesar 0,928 dengan $\rho$ value $0,356(>5 \%)$. Tingkat inflasi yang tinggi menyebabkan harga-harga umum barang menjadi naik atau tinggi. Akibatnya daya beli masyarakat menurun dan secara tak langsung menurunkan pula minat beli investor pada saham perusahaan yang akan go public atau bahkan lebih memilih untuk tidak berinvestasi di pasar saham.

Variabel kurs rupiah memiliki pengaruh positif yang signifikan terhadap underpricing. Hal ini dapat dilihat dari nilai t sebesar 2,619 dan $\rho$ value 0,010 $(<5 \%)$. Kurs merupakan informasi eksternal yang cukup dipertimbangkan dalam perdagangan saham di seluruh dunia tak terkecuali di Indonesia. Arah koefisien yang positif menandakan kurs dengan underpricing memiliki pola searah. Dapat diartikan ketika kurs rupiah menguat maka ada kemungkinan investor untuk berinvestasi dengan membeli saham perusahaan yang akan go public dan begitupun sebaliknya.

\section{REFERENSI}

Ahmad, G. N., Indriyanti, I., \& Buchdadi, A. D. (2013). Pengaruh DER, ROI, Current Ratio dan Rata-rata Kurs terhadap Undepricing pada Initial Public Offering Studi Kasus pada Perusahaan Non Keuangan di Indonesia. JRMSI-Jurnal Riset Manajemen Sains Indonesia, 4(2), 151-166.
Alviani, D., \& Lasmana, A. (2015). Analisis Rasio Keuangan ROA, ROE, Price Earning Ratio terhadap Underpricing Saham Perdana. Studi Kasus: Perusahaan yang Melakukan IPO di BEI Periode 2008-2011. Jurnal Akunida, 1(1), 1-8.

Ardiansyah, M. (2004). Pengaruh Variabel Keuangan terhadap Return Awal dan Return 15 Hari setelah IPO serta Moderasi Besaran Perusahaan terhadap Hubungan antara Variabel Keuangan dengan Return Awal dan Return 15 Hari Setelah IPO di Bursa Efek Jakarta. The Indonesian Journal of Accounting Research, 7(2).

Assari, H. N., Juanda, A., \& Suprapti, E. (2014). Pengaruh Financial Leverage, ROI, ROE, Reputasi Auditor, dan Reputasi Underwriter terhadap Tingkat Underpricing Saham pada Saat IPO di BEI. Jurnal Reviu Akuntansi dan Keuangan, 4(1).

Bachtiar, A. W., \& Syafruddin, M. (2012). Analisis Variabel-variabel yang Mempengaruhi Underpricing pada Saat IPO di Bursa Efek Indonesia Periode 2008-2010. Skripsi. Fakultas Ekonomika dan Bisnis Universitas Diponegoro Semarang.

Baron, D. P. (1982). A Model of the Demand for Investment Banking Advising and Distribution Services for New Issues. The Journal of Finance, 37(4), 955976.

Beatty, R. P. (1989). Auditor Reputation and the Pricing of Initial Public Offerings. Accounting Review, 64(4), 693-709.

Bursa Efek Indonesia. (2019a). Indonesia Capital Market Directory. https:// www.idx.co.id/data-pasar/laporanstatistik/ringkasan-performaperusahaan-tercatat/.

Bursa Efek Indonesia. (2019b). Fact Book. https://www.idx.co.id/data-pasar/ 
laporan-statistik/fact- book/.

Carter, R., \& Manaster, S. (1990). Initial Public Offerings and Underwriter Reputation. Journal of Finance, 45(4), 1045-1067.

Diasih, N. P. P., Wahyuni, M. A., \& Herawati, N. T. (2017). Menguji Informasi Prospektus dan Kondisi Ekonomi Makro terhadap Lebih Tingginya Penawaran Investor pada Saham Emiten di Bursa Efek Indonesia (Studi Empiris pada Perusahaan yang Melakukan IPO Tahun 2012-2016). JIMAT (Jurnal Ilmiah Mahasiswa Akuntansi) Undiksha, 8(2).

Gunarsih, T., Handayani, W., \& Wijayanti, L. E. (2014). Pengaruh Pengungkapan Intellectual Capital dan Kepemilikan Institusi terhadap Underpricing pada Penawaran Umum Perdana. Jurnal Ekonomi dan Bisnis, 15(1), 85-101.

Hanafi, M. (2004). Manajemen Keuangan. Yogyakarta: BPFE.

Handayani, S. R. (2008). Analisis Faktorfaktor yang Mempengaruhi Underpricing pada Penawaran Umum Perdana (Studi Kasus pada Perusahaan Keuangan yang Go Public di Bursa Efek Jakarta Tahun 2000-2006). Tesis. Fakultas Ekonomi Universitas Diponegoro. Semarang.

Hapsari, V. A. (2012). Analisis Faktor-faktor yang Mempengaruhi Underpricing Saham pada Penawaran Umum Perdana di BEI Periode 2008-2010. Skripsi. Fakultas Ekonomi Dan Bisnis Universitas Diponegoro. Semarang.

Hartono, J. (1998). Teori Portofolio dan Analisis Investasi. Yogyakarta: BPFE UGM.

Haska, D., Rokhmawati, A., \& Sjahruddin, S. (2017). Pengaruh Risiko Investasi, Return On Equity (ROE) dan Proceeds Terhadap Underpricing
Dengan Reputasi Underwriter Sebagai Variabel Moderasi Pada Perusahaan Non-Keuangan Yang IPO di BEI Periode 2010-2014. JOM Fekon, 4, 1-14.

Noviani, C. N. (2017). Pengaruh Informasi Keuangan dan Non Keuangan terhadap Underpricing pada Perusahaan yang Melakukan Initial Public Offering (IPO) di Bursa Efek Indonesia (Studi Kasus pada Perusahaan Non Perbankan Periode 2010-2016). Skripsi. Fakultas Ekonomi Dan Bisnis Universitas Islam Negeri Syarif Hidayatullah Jakarta.

Ocktavia, A. (2007). Analisis Pengaruh Nilai Tukar Rupiah/US\$ dan Tingkat Suku Bunga SBI terhadap Indeks Harga Saham Gabungan di Bursa Efek Jakarta Tahun 2003-2005. Skripsi. Universitas Negeri Semarang.

Otoritas Jasa Keuangan. (2016). E-Book Pasar Modal Seri Literasi Keuangan Perguruan Tinggi, 3, 13-93.

Permanisuci, D. D. (2015). Faktor-faktor yang Mempengaruhi Underpricing IPO di Bursa Efek Indonesia Periode 2008-2013. Jurnal Manajemen, 5(1), $18-25$.

Pusat Informasi Go Public Bursa Efek Indonesia. (2019). https://gopublic. idx.co.id/2016/06/22/proses-gopublic/.

Putong, I. (2009). Economics: Pengantar Mikro dan Makro. Jakarta: Mitra Wacana Media.

Rachmadhanto, D. T., \& Raharja. (2014). Analisis Pengaruh Faktor Fundamental Perusahaan dan Kondisi Ekonomi Makro terhadap Tingkat Underpricing Saat Penawaran Umum Perdana (Studi Empiris pada Perusahaan Go Public yang Terdaftar di Bursa Efek Indonesia Tahun 2008 
-2011). Diponegoro Journal of Accounting, 3(4), 1-12.

Ratnasari, A., \& Hudiwinarsih, G. (2013). Analisis Pengaruh Informasi Keuangan, Non Keuangan serta Ekonomi Makro terhadap Underpricing pada Perusahaan Ketika IPO. Buleting Studi Ekonomi, $8(2), 85-97$.

Rosyidah, L. (2014). Pengaruh Karakteristik Perusahaan, Reputasi Underwriter dan Reputasi Auditor terhadap Tingkat Underpricing. Jurnal Ilmu Manajemen (JIM), 2(3), 965-978.

Rock, K. (1986). Why New Issues are Underpriced. Journal of financial economics, 15(1-2), 187-212.

Saefudin. (2018). Apakah Faktor Eksternal Memprediksi Underpricing Lebih Baik Dibandingkan Faktor Internal? Studi Initial Publik Offering di BEI Tahun 2009-2017. Skripsi. Universitas Teknologi Yogyakarta.

Saifudin, S., \& Rahmawati, D. (2016). Pengaruh Informasi Akuntansi dan Non Akuntansi terhadap Underpricing Ketika Initial Public Offering di Bursa Efek Indonesia. Jurnal Penelitan Ekonomi dan Bisnis, 1(1), 33-46.

Sunariyah. (2011). Pengantar Pengetahuan Pasar Modal. Edisi Enam. Yogyakarta: UPP STIM YKPN.

Tandelilin, E. (2010). Portofolio dan Investasi Teori dan Aplikasi. Edisi Pertama. Yogyakarta: Kanisius.

Tinic, S. M. (1988). Anatomy of Initial Public Offerings of Common Stock. The Journal of Finance, 43(4), 789-822.

Undang-Undang No. 8 Tahun 1995 tentang Pasar Modal.

Wahyusari, A. (2013). Analisis Faktor-Faktor yang Mempengaruhi Underpricing Saham Saat IPO di BEI. Accounting
Analysis Journal, 2(4), 386-392.

Wibowo, D. S. (2005). Analisis Faktorfaktor yang Mempengaruhi Tingkat Underpricing pada Perusahaan Perbankan yang IPO Periode 19992003. Tesis. Program Studi Magister Manajemen Program Pasca Sarjana Universitas Diponegoro Semarang.

Wijaya, K. R. (2013). Analisis Faktor Internal dan Eksternal yang Mempengaruhi Underpricing pada Initial Public Offering. Skripsi. Fakultas Ekonomi Universitas Jember.

Yahoo Finance. (2019). Historical Data. https://finance.yahoo.com/.

Yandes, J. (2013). Fenomena Underpricing Saham yang Dipengaruhi Faktor Internal dan Eksternal (Studi pada Perusahaan Go Public yang Terdaftar di BEI Tahun 2007-2010). Skripsi. Fakultas Ilmu Sosial dan Ilmu Politik Universitas Lampung.

Yolana, C., \& Martani, D., (2005). Variabelvariabel yang MMempengaruhi Fenomena Underpricing pada Penawaran Saham Perdana di BEJ Tahun 1994-2001. Jurnal SNA 8. 
